\title{
Environmental Cues and Mechanisms Underpinning Sex Change in Fish
}

\author{
Laura Casas Fran Saborido-Rey \\ Ecology and Marine Resources, Institute of Marine Research (IIM-CSIC), Vigo, Spain
}

\section{Keywords}

Environmental cues · Hermaphroditism · Molecular pathways $\cdot$ Sex change $\cdot$ Steroidogenesis

\begin{abstract}
Fishes are the only vertebrates that undergo sex change during their lifetime, but even within this group, a unique reproductive strategy is displayed by only $1.5 \%$ of the teleosts. This lability in alternating sexual fate is the result of the simultaneous suppression and activation of opposing male and female networks. Here, we provide a brief review summarizing recent advances in our understanding of the environmental cues that trigger sex change and their perception, integration, and translation into molecular cascades that convert the sex of an individual. We particularly focus on molecular events underpinning the complex behavioral and morphological transformation involved in sex change, dissecting the main molecular players and regulatory networks that shape the transformation of one sex into the opposite. We show that histological changes and molecular pathways governing gonadal reorganization are better described than the neuroendocrine basis of sex change and that, despite important advances, information is lacking for the majority of hermaphrodite species. We highlight significant gaps in our knowledge of how sex change takes place and suggest future research directions.
\end{abstract}

(C) 2021 The Author(s)

Published by S. Karger AG, Basel

karger@karger.com www.karger.com/sxd

Karger $\stackrel{\text { ' }}{5}$
(C) 2021 The Author(s)

Published by S. Karger AG, Basel

This is an Open Access article licensed under the Creative Common Attribution-NonCommercial-4.0 International License (CC BY-NC) (http://www.karger.com/Services/OpenAccessLicense), applicable to the online version of the article only. Usage and distribution for commercial purposes requires written permission.
Teleost fishes exhibit the largest array of reproductive strategies among vertebrates and are the only lineage to display hermaphroditism, defined by the presence of both male and female reproductive function in a single individual [Sadovy De Mitcheson and Liu, 2008]. This unique strategy has fascinated scientists for decades, and significant research efforts have been conducted to decipher the biological, ecological, and evolutionary aspects of this labile adaptation within fish [Warner, 1988a; Shapiro, 1989; Ross, 1990; Avise and Mank, 2009; Avise, 2010; Erisman et al., 2013].

Hermaphroditism can manifest in 2 modes. Simultaneous (synchronous) hermaphrodites possess fully functional male and female gonads concurrently although self-fertilization rarely occurs in fishes [Avise, 2010]. They are far less common than sequential hermaphrodites, which change sex during their lifetime. Change can occur from male to female (protandrous), from female to male (protogynous), or serially (bidirectional sex changers).

A recent review provides a thorough updated list of hermaphroditic fish species [Kuwamura et al., 2020], increasing the number of families with confirmed hermaphroditism by one-third compared to the previous inventory [Sadovy De Mitcheson and Liu, 2008]. A total of 462 species from 41 families and 17 orders display this reproductive strategy, accounting for about $1.5 \%$ of teleosts [Nelson et al., 2016; Kuwamura et al., 2020]. Over

Correspondence to:

Laura Casas, lauracasas@iim.csic.es 
$88 \%$ correspond to sequential hermaphrodites, and there is a striking dominance of protogyny (305 species) over protandry (54 species) and bidirectional sex changers (66 species). The marine realm is the natural habitat of most sequential hermaphrodites, the majority occurring on coral reefs and only $2 \%$ of them inhabiting fresh waters [Pandian, 2010; Kuwamura et al., 2020]. By contrast, freshwater species account for $43 \%$ of all known fish species although the constraints preventing the evolution of hermaphroditism in this environment are unknown.

Despite the classical view indicating that hermaphroditism has evolved repeatedly and independently in multiple not-closely related lineages across teleosts [Sadovy De Mitcheson and Liu, 2008; Avise and Mank, 2009; Erisman et al., 2013], this might only be true for protogynous species since protandry and bidirectional sex change seem to be restricted to 4 lineages of Percomorpha [Kuwamura et al., 2020].

This review focuses on recent advances in our understanding of the biological processes underpinning sex change in sequential hermaphrodites, emphasizing the molecular aspects regulating a radical transformation of behavior, morphology, and restructuring of the gonads. We provide an overview of the sequential modifications that occur during sex change, from the integration of the cues triggering sex change at the brain level to the subsequent gonadal reorganization, summarizing the current knowledge. Most research to date has focussed on social species, especially the bluehead wrasse, a key model in sex change, and clownfishes to a less extent, but this review includes all known information on sequential hermaphrodites.

\section{When, Where to, and Why Change Sex?}

The theory of the size-advantage model (SAM) has been widely used to explain the overall occurrence of sex change and to predict the timing and direction of the switch [Ghiselin, 1969; Warner, 1975, 1988b; Munday et al., 2006; Kazancioĝlu and Alonzo, 2010; Erisman et al., 2013]. According to SAM, sex change should be favored when larger body sizes increase the reproductive success of the opposite sex over the initial sex. Thus, sex change is timed to maximize the expected lifetime reproductive output of the individual.

The benefits of the model are tightly linked to the reproductive system and social structure of the species [Munday et al., 2006]. Protogynous species tend to display haremic polygyny, conforming well to the SAM predictions. The reproductive value for males increases more with size than for the opposite sex since they monopolize reproductive access to several females [Warner, 1988a; Lutnesky, 1994; Erisman et al., 2009; Hodge et al., 2020]. The largest female of the group undergoes sex change following the disappearance of the socially dominant male. Protandry is favored when reproductive fitness for females increases more with body size than for males. It has been typically reported in monogamous species but also in species displaying random mating with low sperm competition (e.g., several sparids) [Sadovy De Mitcheson and Liu, 2008]. Both are consistent with the SAM expectations although males need a disproportionally high investment in sperm production to compensate for their reduced size and allow fertilization of highly fecund females [Molloy et al., 2007; Pla et al., 2020]. In protandrous and monogamous species, the timing of sex change is controlled socially and follows the loss of the dominant female. In species displaying random mating sex change is often associated with reaching a threshold body size or critical age [Warner, 1988b; Pla et al., 2020].

Although the SAM model explains patterns of sex change in many sequential hermaphrodites successfully, several exceptions do not conform to theoretical SAM expectations. The largest females of some protogynous species do not always change sex [Lutnesky, 1994; Cole and Shapiro, 1995; Munoz, 2004; Clifton and Rogers, 2008; Avise and Mank, 2009], and monogamy has been described in various protogynous species [Kuwamura et al., 2020]. In addition, the patterns of sex change in bidirectional hermaphrodites are not always consistent with SAM. Bidirectional sex change might be favored under high risk of predation that prevents the movement to find new breeding opportunities, resulting in a substantial loss of reproductive output. It also appears to be related to unpredictable changes in social organization [for an extended review, see Munday et al., 2010 ]. These deviations suggest that sex change in fish might be more complicated than originally anticipated by the model. The incorporation of several factors such as sperm competition have been proposed in order to adjust the model to all the patterns seen in nature [Muñoz and Warner, 2003; Pla et al., 2020].

\section{Environmental Cues Triggering Sex Change and Their Perception}

Environmental cues triggering sex change differ among species but are typically either size (and/or age) dependent or due to changes in social structure [Godwin, 2009; Kobayashi et al., 2013]. Most protandrous species 
need to attain a critical age or size to initiate sex change, and eventually all individuals in a population will transition to females. Clownfishes (subfamily Amphiprioninae) constitute an exception since sex change is controlled socially. Protogynous species display mostly polygynous mating systems, and sex change is mediated by variations in the social context [Warner, 1984; Kuwamura and Nakashima, 1998; Munday et al., 2006]. The sex ratio of a social group, the demography (size distribution), the density, and the biomass are all factors that affect the dynamics and timing of sex change producing significant variation within and between species [Warner, 1988a; Warner and Swearer, 1991; Buston, 2003; Munday et al., 2006; Ferreira et al., 2010; Taylor, 2014; Chen et al., 2020a]. Detailed studies are lacking for most sequential hermaphrodites, and even less is known about the perception of these environmental cues. In socially controlled sex change, individuals depend on social stimuli, e.g., disappearance of dominant conspecific(s), to trigger the transformation, but the basic functioning of this process remains unanswered. Whether this social stimulus is perceived through the visual, olfactory, auditory, and/or tactile systems is yet a major challenge (Fig. 1). The little information we have derived mostly from studies on social status and courtship behavior in gonochoristic fish, mainly in cichlid species [EscobarCamacho and Carleton, 2015]. Visual cues alone in Astatotilapia burtoni significantly influence behavior and reproductive physiology [Grosenick et al., 2007; Chen and Fernald, 2011], but they also use olfactory and auditory cues to signal social rank and during courtship [Maruska and Fernald, 2010, 2012; Maruska et al., 2012; Nikonov and Maruska, 2019]. Another cichlid, Oreochromis mossambicus, communicates social dominance through odorant signals [Barata et al., 2007, 2008; Simões et al., 2015] and relies heavily on acoustic signaling during courtship [Amorim et al., 2003]. Acoustic communication is indeed widespread in fishes and essential for the reproductive and social behavior in many species [reviewed by Amorim et al., 2015], including protandrous clownfishes [Parmentier et al., 2007; Colleye et al., 2009; Colleye and Parmentier, 2012]. Similarly, a large number of species employ tactile stimulation during courtship [reviewed by Kasumyan, 2011]. In protogynous gobies, visual and olfactory cues have been shown to induce sex change although sex- and species-specific differences were observed [Cole and Shapiro, 1992, 1995; Lorenzi et al., 2006]. Visual, olfactory, and tactile cues are suspected to regulate sex change in protogynous black-spot tuskfish [Sato et al., 2018].

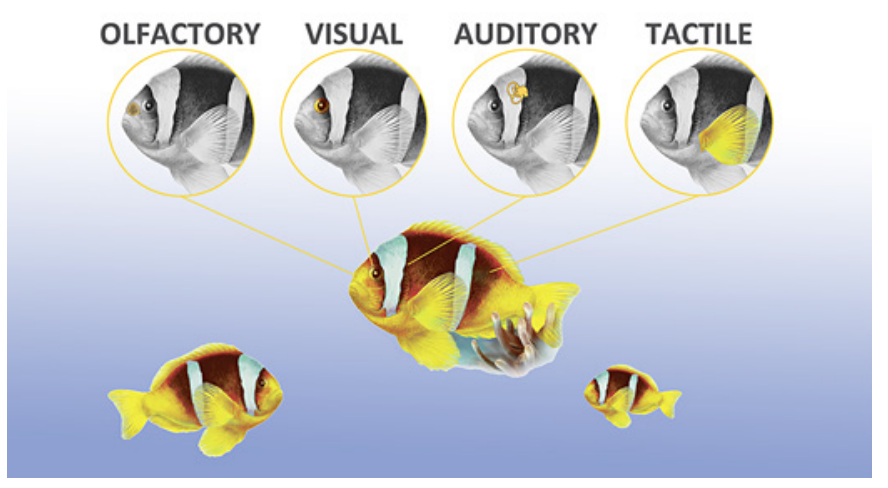

Fig. 1. Schematic representation of sensory modalities upon which hermaphrodites rely on the perception of social stimuli to initiate sex change. The relative hierarchy among sensory channels is dependent on habitat, social organization, and reproductive strategy. In monogamous Red Sea clownfish, for instance, disappearance of the dominant female triggers sex change only if a smaller conspecific is present to complete the breeding pair.

Data from gonochoristic and hermaphrodite species indicate that social communication in fishes is often multisensory, but a comprehensive analysis to elucidate the role of all these signals in sex change is lacking. Visual signals likely play a predominant role in many hermaphrodite species, but the relative hierarchy among sensory modalities is dependent on the social organization and the reproductive strategy. Moreover, differences within species might occur, since the habitat and environmental conditions where the specimens live dictate the effectiveness of the transmission via different sensory channels [Maruska et al., 2019].

\section{Signaling Axis and the Steroidogenic Machinery in Sex Change}

Environmental cues ensue rapid neurochemical changes in the brain to adjust the behavior of social sex changers within minutes to hours when the dominant hierarchy is altered. Subsequently, changes in the brain are transmitted to the gonads ensuing a dramatic reorganization of the gonadal tissue. Gonadal changes usually take considerably longer [Warner and Swearer, 1991; Godwin, 2009; Casas et al., 2016; Dodd et al., 2019; Todd et al., 2019], and their surgical removal does not prevent or discernibly alter behavioral shifts at the brain level [Godwin et al., 1996; Semsar and Godwin, 2003]. 
The established view proposes the hypothalamic pituitary gonadal (HPG) axis as the major signaling pathway regulating sex change in hermaphrodite fish. The HPG axis is ultimately responsible for the estrogen-androgen balance that drives gonadal fate [reviewed by Lamm et al., 2015]. The hypothalamus releases gonadotropin releasing hormones $(\mathrm{GnRH})$ in the brain, stimulating the pituitary to synthetize and secrete the 2 gonadotropins (GtHs) - luteinizing hormone and follicle stimulating hormone - into the blood system, both key in the control of reproduction of vertebrates [Clayton et al., 1982]. Subsequently, GtHs regulate the production of sex hormones in the gonad via their receptors, either follicle cells in the ovary or Leydig cells in the testis [Devlin and Nagahama, 2002; Weltzien et al., 2004; Todd et al., 2016].

In teleosts, $17 \beta$-estradiol (E2) and 11-ketotestosterone $(11-\mathrm{KT})$ are the main estrogens and androgens, respectively [Frisch, 2004; Guiguen et al., 2010]. During sex change, remarkable shifts in E2 and 11-KT levels occur, with protogynous and protandrous species showing reverse profiles [reviewed by Godwin, 2010]. Protogynous sex change is characterized by elevated levels of E2, followed by a steady increase in 11-KT paralleled by ovarian atresia and proliferation of spermatogonia [Ohta et al., 2008; Muncaster et al., 2013; Todd et al., 2019]. Conversely, protandrous species show a decrease in 11-KT levels preceding E2 increases across sex change [Godwin and Thomas, 1993; Lee et al., 2001]. Bidirectional sex changers show higher concentrations of E2 in females compared to males but no significant differences in 11-KT [Kroon et al., 2003; Lorenzi et al., 2012]. Several manipulative studies have demonstrated the role of the HPG axis in controlling the gonadal fate through the E2-11-KT balance. Administration of $\mathrm{GnRH}$ and gonadotropins alters E2 and 11-KT levels, inducing gonadal sex change in protandrous black porgy and gilthead seabream [Du et al., 2005; Wong et al., 2006; Godwin, 2010]. In protogynous wrasses, administration of E2 induces male-to-female sex change [Kojima et al., 2008; Miyake et al., 2008]. Manipulation of the E2 levels via the aromatase pathway in bidirectional gobies results in protandrous sex change when E2 is increased and protogynous sex change following the decrease of E2 [Kroon et al., 2005].

In addition to the HPG axis, the hypothalamic-pituitary-interrenal (HPI) axis has been recently proposed to play a critical role in the regulation of sex change in protogynous hermaphrodites. Cortisol is the main signaling hormone of the HPI axis and regulates stressinduced responses in all vertebrates [for an extended review, see Goikoetxea et al., 2017]. This glucocorticoid causes masculinization of female gonochoristic fish under thermal stress [Hattori et al., 2009; Hayashi et al., 2010; Yamaguchi et al., 2010; Adolfi et al., 2019a]. Administration of oral cortisol induces female-to-male sex change in protogynous hermaphrodites [Frisch et al., 2007; Nozu and Nakamura, 2015; Chen et al., 2020b], while in protandrous fish it seems to prevent sex change [Iwata and Suzuki, 2020]. Nonetheless, an increase in cortisol levels or the expression of cortisol pathway genes has been described in both social protandrous and protogynous hermaphrodites following the removal of the dominant conspecific [Godwin, 1994; Solomon-Lane et al., 2013; Todd et al., 2019], highlighting the need for further research.

In line with the view that sex change is mechanistically linked with physiological stress is the model proposing that biochemical sensors act as transducers of the environmental cues that trigger the process [Castelli et al., 2020]. According to the CaRe model, highly conserved ancestral elements of calcium $(\mathrm{Ca})$ and redox $(\mathrm{Re})$ status would be acting synergistically with the HPI axis in initiating, maintaining, or mediating sex change. Additional studies are needed to clarify the role of these mechanisms in sex change, establish whether they are evolutionarily conserved in protandrous and protogynous species, and elucidate the degree of interplay exhibited between CaResensitive pathways, the HPI, and the HPG axis.

\section{Neuroendocrine Mechanisms Underlying Sex Change}

The neuroendocrine molecular mechanisms underlying the perception and integration of social stimuli and how they feedback on the brain to promote fine-tuned behavioral shifts and ensue sex change are yet a major challenge. Most information derives from studies of single or few key genes known to be involved in social behavior or sexual development in vertebrates. More recent analysis of global gene expression using transcriptomics have proved inefficient in revealing changes in expression of known key neural regulators, possibly reflecting the subtle or highly localized nature of neural signals [Casas et al., 2016; Todd et al., 2019].

Several neuropeptides known to act as key regulators of the HPG axis and/or modulation of behavior have been proposed to be involved in sex change in fish. The neurotransmitters arginine vasotocin (AVT) and isotocin (IT) are well-studied modulators of social behavior across vertebrates [Black et al., 2004; Godwin and Thompson, 

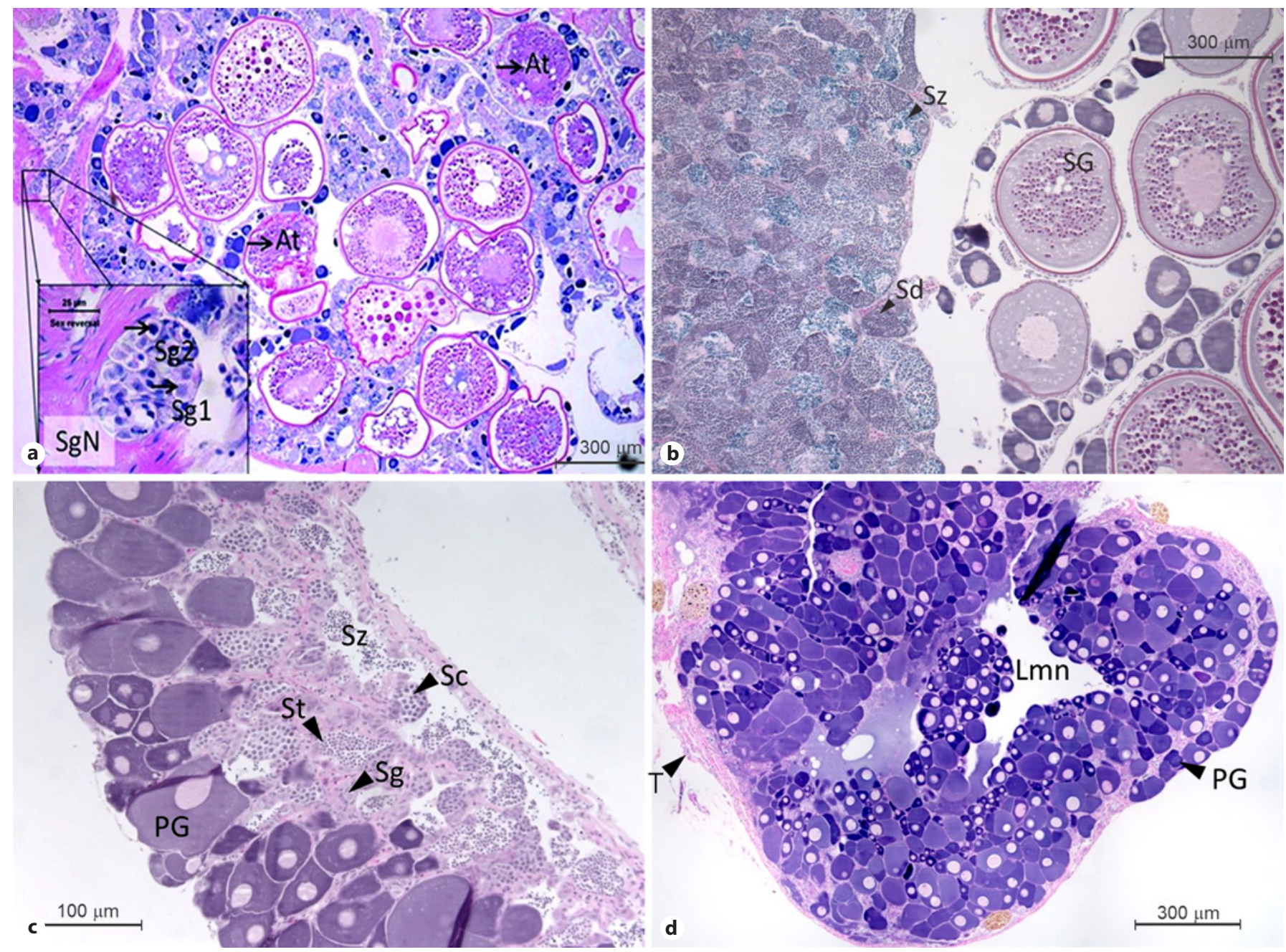

Fig. 2. Histological sections illustrating sex change. a Protogynous mature rainbow wrasse (Coris julis) female at initial stages of transition phase displaying ovarian degeneration with atretic follicle (At) and proliferation of spermatogonial nests ( $\mathrm{SgN}$; Sg1, primary spermatogonia, Sg2, secondary spermatogonia). b Simultaneous hermaphrodite painted comber (Serranus scriba) where secondary growth oocytes (SG), spermatids (St), and spermatozoa (Sz) are found concurrently. c Protandrous mature clownfish (Amphiprion

2012; Deangelis et al., 2017; ]. Structural changes in AVT/ IT neurons or differential expression has been correlated with social dominance hierarchies and aggression in various sequential hermaphrodites, including several tropical wrasses [Godwin and Thompson, 2012; Thomas et al., 2019; Todd et al., 2019], the bluebanded goby [Black et al., 2004], and clownfishes [Iwata et al., 2010; DeAngelis et al., 2020]. Changes in other neuropeptides such as kisspeptins [Shi et al., 2010] and norepinephrine have also been proposed to regulate sex change but their precise

bicinctus) male with functional testes including all stages of spermatogenesis (Sc, spermatocytes) and immature ovary containing only primary growth oocytes (PG). d Protandrous transitional clownfish, where testicular tissue $(\mathrm{T})$ is restricted to a small portion in the periphery of the gonad, highly degenerated and contains no germ cells, while the lumen of the ovary $(\mathrm{Lmn})$ is visible, but only PG oocytes are present.

roles remain unclear [Godwin, 2010; Larson, 2011; Lamm et al., 2015; Liu et al., 2017].

The gonadotropin-releasing hormone $(\mathrm{GnRH})$ and their receptors are also well-conserved components of the neural molecular machinery. Their expression fluctuates during sex change in protogynous [Kobayashi et al., 2010], protandrous [An et al., 2008, 2010], and bidirectional [Kobayashi et al., 2009] hermaphrodites, but their patterns are inconsistent across species [reviewed in Lamm et al., 2015]. The brain aromatase, on the other 
hand, is a key enzyme that regulates the balance of sex steroids, and its expression has been shown to increase across sex change in protandrous fish [Casas et al., 2016] and decrease sharply at the beginning of sex change in protogynous fish [Todd et al., 2019].

\section{Gonadal Restructuring during Sex Change}

Changes in the brain are transmitted to the gonads ensuing a dramatic reorganization of the gonadal tissue. Several restructuring patterns can be found among hermaphroditic teleosts, reflecting the diversity of hermaphroditism types and evolutionary origin [see Gemmell et al., 2019 and references therein].

In many species, juveniles develop only ovaries (protogynous) or testes (protandrous) containing gonadotropin-independent gametes [i.e., oogonia and primary growth (PG) oocytes in females and primary spermatogonia in males]. At the onset of sexual maturation, gamete development becomes gonadotropin-dependent, and females start to produce vitellogenic oocytes and then ovules, while males produce spermatocytes and then spermatozoids. Before sex change, no testicular tissues are detectable in the ovary and vice versa [Sadovy and Shapiro, 1987]. At the time fish begin to change sex, they enter the transition phase [Brown-Peterson et al., 2011], which is characterized by the degeneration of the initial gender tissue, concurrently with the ripening of the terminal gender (Fig. 2a). This is a very complex process at a structural, hormonal, and molecular level as it involves atresia of gametes of one sex and proliferation of gonadotropin-dependent growth of gametes of the other sex. It is still unknown from where and what gonadal cell type the new gonadal tissue originates. After sex change is completed, the initial gender tissue is completely resorpted or only small remnants are visible. This pattern has been observed in protandrous species (e.g., Centropomus undecimalis) [Taylor et al., 2000], but it is most commonly observed in protogynous fish (e.g., Labrus bergylta) [Villegas-Ríos et al., 2013].

In some species, juveniles develop a bisexual gonad or ovotestis, where testicular and ovarian tissues are found well-separated within the same organ and often, but not always, isolated by connective tissue [Sadovy De Mitcheson and Liu, 2008]. Oogonia and PG oocytes in the ovary and spermatogonia and spermatocytes in the testis are visible. In simultaneous hermaphrodites at the onset of sexual maturation both tissues develop into functional ovaries and testis capable of producing gametes during the same spawning season along the entire reproductive lifetime (Fig. 2b), having therefore a permanent ovotestis (e.g., Serranus scriba) [Alonso-Fernández et al., 2011]. Similarly, in bidirectional hermaphrodites ovotestis are permanent, but the gonad is unable to produce gametes simultaneously, and sex change means a mere shift in functionality where one tissue is capable to produce gametes and the other remains inactive [Kobayashi et al., 2005]. However, in sequential hermaphrodites with ovotestis (Fig. 2c) the initial gender tissue degenerates concurrently with the proliferation of the final sex tissue during sex change (Fig. $2 \mathrm{~d}$ ). This is most commonly observed in protandrous species (e.g., clownfishes) [Casadevall et al., 2009; Casas et al., 2016] and likely associated with the costs of producing oocytes. Before sex change, the testis is very active producing gametes; however, the ovary, remaining immature, is not completely inactive since oogonia and PG oocytes proliferate as a preparation for the sex change. Hence, there are hormonal and molecular activities in the whole ovotestis for both sexes.

The timing and rate at which one tissue degenerates and the other develops (having or not having ovotestis) differs greatly among species, from days to months [Thomas et al., 2018]. It depends on the reproductive mode as well environmental and social factors, but most commonly, the degeneration is almost completed before the terminal sex becomes sexually mature or competent.

\section{Molecular Regulation Underpinning Gonadal Sex Change: Do Protogyny and Protandry Share a Mirrored Molecular Mechanism?}

It is widely recognized that the maintenance of the sexual identity of ovary and testis in vertebrates is dependent on male and female pathways acting antagonistically. Thus, gonadal fate is actively regulated not only by the activation of the appropriate sex-specific network but also by the suppression of the sex-opposing network [Capel, 2017].

Until recently, most studies investigated the role in sex change of single or few genes known to be involved in sex determination and differentiation in vertebrates [Miyaki et al., 2012; Thomas et al., 2019; Peng et al., 2020]. The advent of new genomic technologies enabled transcriptomic studies of global gene expression profiles that significantly contributed to our understanding of how sex change is initiated and regulated at the molecular level. Several studies compared male and female expression in hermaphrodite fish species, providing further evidence of 
the importance of well-known molecular players in preserving gonadal sex identity [Manousaki et al., 2014; Liu et al., 2015; Tsakogiannis et al., 2018]. Nonetheless, it was the study of transitional stages across sex change, first in clownfish and later in bluehead wrasse, that led to the unveiling of a large number of novel candidate genes potentially implicated in sex change [Casas et al., 2016; Todd et al., 2019].

Within the feminizing pathway, a fundamental gene for the maintenance of the ovarian function is gonadal aromatase (cyp19a1a), an enzyme responsible for catalyzing the conversion of androgens into estrogens [Guiguen et al., 2010]. A strong female-biased expression and a rapid decrease of aromatase expression levels at the beginning of sex change has been described in protogynous species [Liu et al., 2015; Todd et al., 2019; Tsakogiannis et al., 2019]. Conversely, aromatase expression is sharply upregulated at the onset of male-to-female sex change [Wu et al., 2010b; Ravi et al., 2014; Casas et al., 2016] (Fig. 3). The aromatase gene has been proposed to play a central role in protandrous and protogynous sex changers, acting as the potential switch of gonadal sex change by causing the rise or collapse of estrogen production and consequently activating the feminizing and masculinizing pathway, respectively [Casas et al., 2016; Todd et al., 2019]. Administration of aromatase inhibitors blocks/induces sex change in protandrous and protogynous hermaphrodites, respectively [Lee et al., 2002; Horiguchi et al., 2018; Breton et al., 2019].

Transcription factor foxl2 (forkhead transcriptional factor L2) is also vital for the maintenance of the ovarian pathway and the suppression of the male network [Siegfried, 2010; Georges et al., 2014]. It is involved in modulation of aromatase expression and hence estrogen synthesis, suggesting a feedback loop between both [Wang et al., 2007; Yamaguchi et al., 2007; Guiguen et al., 2010]. This positive loop is reflected in a high correlation of the spatial and temporal expression profiles of foxl2 and cyp19a1a in gonochoristic fish during gonadal differentiation [Baron et al., 2004; Nakamoto et al., 2006] and in protandrous clownfish during sex change [Casas et al., 2016]. Expression patterns in the protogynous bluehead wrasse do not seem to be as tightly coupled, showing only partially overlapping profiles. Aromatase expression is rapidly downregulated in transitioning females, while foxl2 levels are maintained across sex change and only arrested in terminal males [Todd et al., 2019] (Fig. 3). Other key players that regulate ovarian steroidogenesis and are activators of the feminizing pathway are the steroidogenic factor $s f 1$, the steroidogenic acute regulatory protein Star, and the enzyme estradiol $17 \beta$-dehydrogenase $h s d 17 b$, all involved in steroid hormone synthesis [reviewed by Rajakumar and Senthilkumaran, 2020]. These genes show clear sex-specific differences in expression in both protandrous and protogynous hermaphrodites across sex change (e.g., $h d s 17 b$; Fig. 3). Moreover, genes involved in the Rspo1/Wnt/ $\beta$-catenin signaling (e.g., rspo1, wnt $4 b, f s t$ ), known to regulate ovarian differentiation in mammals [Ungewitter and Yao, 2013], have been implicated in sex change in some hermaphrodites [Casas et al., 2016; Tsakogiannis et al., 2018]. In others, however, an unexpected male-biased expression was detected [Liu et al., 2015], highlighting the need to better characterize their functions in teleosts. Todd and collaborators provided an appealing explanation consisting in the duplication and neofunctionalization of genes involved in sexual pathways [Todd et al., 2019].

The male-promoting network is composed, in turn, of various conserved components in sex determination, testicular differentiation, and spermatogenesis in teleosts. Doublesex and mab-3-related transcription factor 1 $(d m r t 1)$ plays a pivotal role in the differentiation and maintenance of the gonadal male identity across vertebrates [Matson and Zarkower, 2012]. Its expression has been described as male-restricted or strongly male-biased in at least 20 gonochoristic fish species [see review by Herpin and Schartl, 2011 and references therein]. Mutations of dmrt1 in medaka and zebrafish lead to either male-to female reversal or dysfunctional males [Masuyama et al., 2012; Lin et al., 2017; Webster et al., 2017]. Studies in diverse animals from mammals to fish have demonstrated an antagonistic relationship between $d m r t 1$ and foxl 2 that is essential for the maintenance of gonadal fate [Matson et al., 2011; Li et al., 2013]. Opposite expression profiles characterize $d m r t 1$ during sex change in protogynous and protandrous species, paralleling closely the development or regression of the testes, respectively (Fig. 3) [He et al., 2003; Huang, 2005; Xia et al., 2007; Alam et al., 2008; Casas et al., 2016; Chen et al., 2019; Todd et al., 2019; Zhang et al., 2019].

The anti-Müllerian hormone $(a m h)$ gene is another essential member of the male pathway contributing to male sexual differentiation in fish [Pfennig et al., 2015; Adolfi et al., 2019b]. Mutations of $a m h$ induce male-tofemale change in medaka and pufferfish [Morinaga et al., 2007; Kamiya et al., 2012; Nakamura et al., 2012]. Overexpression causes, in turn, female-to-male reversal in orange-spotted grouper [Han et al., 2018]. Moreover, recombinant amh impairs spermatogenesis and arrests proliferation of spermatogonia in gonochoristic and her- 
Fig. 3. Expression patterns of selected gonadal key genes across sex change in protogynous bluehead wrasse (blue) [data from Todd et al., 2019] and protandrous clownfish (orange) [data from Casas et al., 2016]. Vertical axes show normalized gene expression levels. The bottom gene graph represents sox 9 expression in wrasse and sox8 in clownfish.

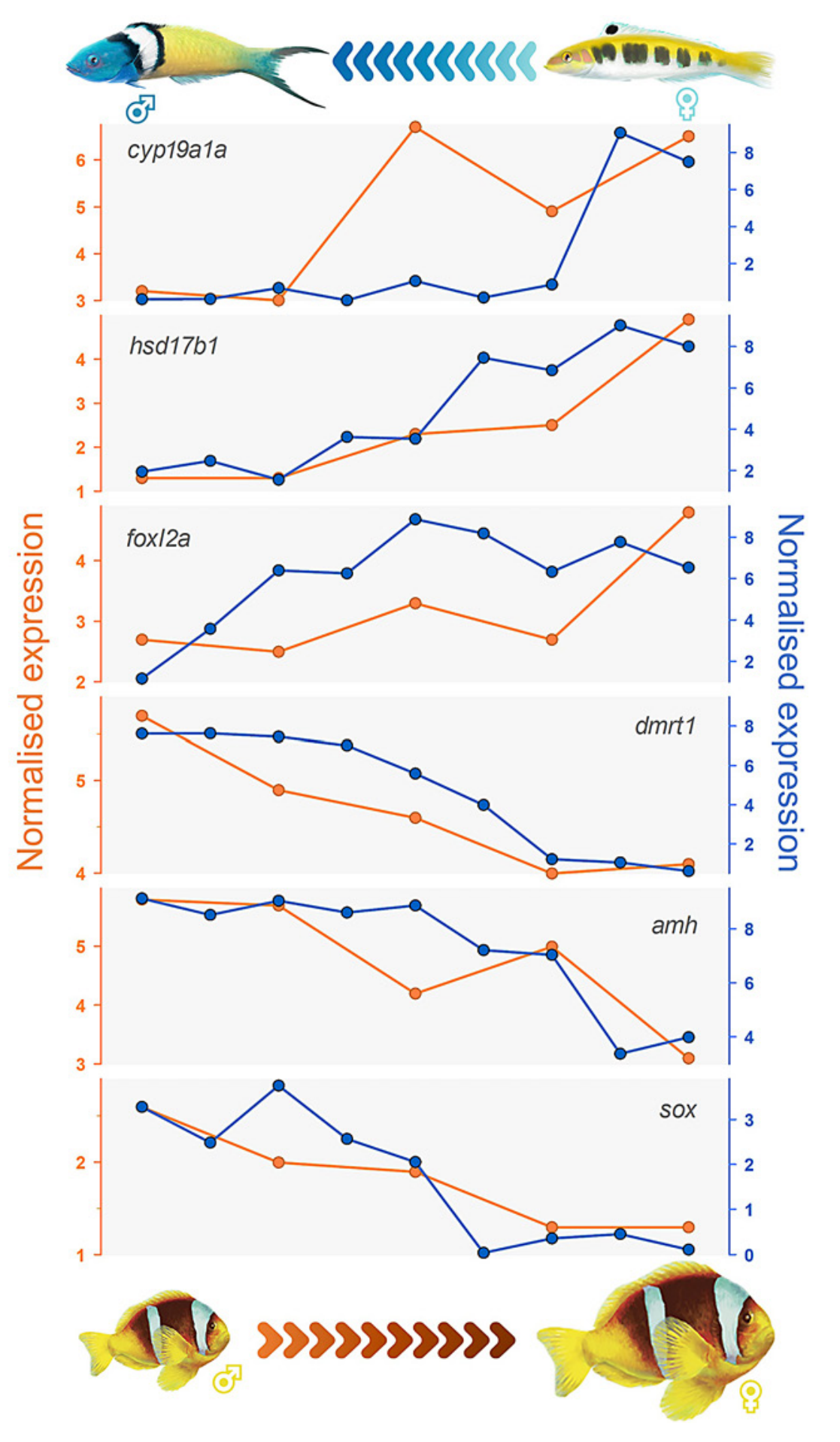

maphrodite fish [Shiraishi et al., 2008; Skaar et al., 2011; $\mathrm{Wu}$ et al., 2015]. Remarkable differences in expression between both sexes have been described in both protogynous and protandrous teleosts, and amh expression pro- files throughout sex change follow closely those of $d m r t 1$ (Fig. 3) [Wu et al., 2010a, 2017; Casas et al., 2016; Todd et al., 2019; Zhang et al., 2019]. 
The expression of $a m h$ is regulated by several members of the Sox gene family, an ancient group of transcription factors that encode key mediators of sex determination and differentiation in mammals. The organization and function of this large family is poorly understood in other types of vertebrates, including fish, but some members are well-conserved and widely distributed. The genes sox9, sox 8 , and sox 3 are commonly expressed in the gonads of all fish species studied to date, showing a clear sex-biased expression in hermaphrodite species. The expression of sox9 has been reported as either male-restricted or as strongly male-biased in at least 10 hermaphrodite species, including protogynus and protandrous fish (Fig. 3) [Manousaki et al., 2014; Liu et al., 2015; Tsakogiannis et al., 2018, 2019]. Sox3 has shown a remarkable female-biased expression in common Pandora, red porgy, and other 5 sparids, but information in other fish families is lacking [Tsakogiannis et al., 2018, 2019]. Sox8 has been proposed as an important determinant for the maintenance of testis cell identity in protandrous clownfish (Fig. 3), although its expression is female-specific in the protandrous gilthead seabream, suggesting a variable species-specific role [Casas et al., 2016; Tsakogiannis et al., 2019].

Despite strong evidence of the implication of described molecular players in sex change in fish, the precise organization of the gene network directing sex reprogramming has not been elucidated in any hermaphrodite fish species yet. Novel molecular players have been proposed recently [Casas et al., 2016; Todd et al., 2019], but their functions and possible evolutionarily conserved roles remain unexplored.

\section{The Epigenetic Regulation of Sex Change}

The sexual phenotype is not only the result of genetic pathways but also of environmental influences and epigenetic regulations [Capel, 2017]. These regulations include several types of epigenetic modifications, specifically DNA methylation, histone modifications, and non-coding RNAs, the first 2 being better studied and understood [for a comprehensive review, see Best et al., 2018]. Few studies have assessed epigenetic regulation of sex change in gonochoristic and hermaphrodite species and a systemic analysis is lacking [for an extended review, see Ortega-Recalde et al., 2020]. Most research to date has addressed the analysis of methylation patterns in individual genes, mainly those with a well-known role in sex change in the gonads (see previous section). Expression of cyp19a1a was inversely correlated with methylation levels across sex change in protandrous black porgy [Wu et al., 2016], protogynous ricefield eel, and bluehead wrasse [Zhang et al., 2013; Todd et al., 2019], but not in protandrous barramundi [Domingos et al., 2018]. Similarly, progressive methylation/demethylation of $d m r t 1$ is observed across sex change in protandrous and protogynous hermaphrodites, respectively [Domingos et al., 2018; Todd et al., 2019].

The most complete study to date used whole-genome analysis in bluehead wrasse across sex change revealing distinctive spatiotemporal epigenetic patterns associated with the transformation of ovaries into testes [Todd et al., 2019]. Key epigenetic modifiers, including members of the DNA methylation machinery (such as tet 1, tet2, tet3 and dnmt1, dnmt3 genes), were shown to fluctuate throughout gonadal restructuring. Moreover, other epigenetic mechanisms, including histone acetyltransferases and deacetylases and polycomb group $(\mathrm{PcG})$ genes, were dynamically regulated during female-to-male sex change. These results suggest a genome-wide DNA methylation reprogramming event. Histone modifications have also been linked to initiating and maintaining the gonadal identity in other sex-changing species [Zhang et al., 2013; Tsakogiannis et al., 2019].

Altogether, existing data seem to indicate a key role of epigenetic mechanisms in both maintenance of sexual identity and in reprogramming of sexual fate. However, information is lacking for the majority of hermaphrodite species. Moreover, we have a poor understanding of the mechanistic and synergistic action of these modifications in the gonad, while at the brain level no studies have been undertaken in hermaphrodites. Data from mammals provide evidence of an important role of DNA methylation in sexual differentiation of the brain [Forger, 2016; Ratnu et al., 2017], while recent studies in several gonochoristic fish species suggest an involvement of epigenetic mechanisms in response to social interaction [Best et al., 2018]. In cichlids, socially dominant behavior was inhibited by administration of a pharmacological treatment that reduced global methylation [Lenkov et al., 2015]. In addition, epigenetic reprogramming was identified as a key mechanism underlying differential social behavior in adults exposed to different early life social environments [Taborsky et al., 2013].

\section{Conclusions}

Despite intense research, we are still in the infancy of understanding the process of sex change from a global perspective. Significant gaps remain in our knowledge of 
the perception of environmental cues and how they are mediated by the social context, the mechanisms underlying their integration and processing at the brain level, and the exact roles of well-known players at the gonadal level. Most of the data to date is restricted to the detection of changes in gene expression and needs to be validated by functional experiments. Genome editing technologies offer the possibility of directly targeting and modifying genes to elucidate their contribution to the sex change process. Current knowledge is based on the study of few species, emphasizing the need to extend the scope to other sex changers to elucidate evolutionarily conserved networks across hermaphrodites. A deeper insight into the molecular and epigenetic mechanisms governing sex change is essential to understand how this biological process might be affected in a changing environment.

\section{Acknowledgement}

We thank Manfred Schartl for inviting us to contribute this review article. We are also grateful to Sergio Casas for providing the fish drawings displayed in the figures.

\section{Conflict of Interest Statement}

The authors have no conflicts of interest to declare.

\section{References}

Adolfi MC, Fischer P, Herpin A, Regensburger M, Kikuchi M, Tanaka M, et al. Increase of cortisol levels after temperature stress activates dmrtla causing female-to-male sex reversal and reduced germ cell number in medaka. Mol Reprod Dev. 2019a;86(10):1405-17.

Adolfi MC, Nakajima RT, Nóbrega RH, Schartl M. Intersex, hermaphroditism, and gonadal plasticity in vertebrates: evolution of the müllerian duct and Amh/Amhr2 signaling. Annu Rev Anim Biosci. 2019b;7:149-72.

Alam MA, Kobayashi Y, Horiguchi R, Hirai T, Nakamura M. Molecular cloning and quantitative expression of sexually dimorphic markers Dmrt1 and Foxl2 during female-to-male sex change in Epinephelus merra. Gen Comp Endocrinol. 2008;157(1):75-85.

Alonso-Fernández A, Alós J, Grau A, Domínguez-Petit R, Saborido-Rey F. The use of histological techniques to study the reproductive biology of the hermaphroditic mediterranean fishes Coris julis,Serranus scriba, and Diplodus annularis. Mar Coast Fish. 2011;3(1): 145-59.

Amorim MCP, Fonseca PJ, Almada VC. Sound production during courtship and spawning of Oreochromis mossambicus: male-female and male-male interactions. J Fish Biol. 2003;62: 658-72.

Amorim MCP, Vasconcelos RO, Fonseca PJ. Fish Sounds and Mate Choice. In: Ladich F, editor. Sound Communication in Fishes. Animal Signals and Communication, Vol 4. Vienna: Springer; 2015. p. 1-33.

An KW, Nelson ER, Habibi HR, Choi CY. Molecular characterization and expression of three GnRH forms mRNA during gonad sexchange process, and effect of GnRHa on GTH subunits mRNA in the protandrous black porgy (Acanthopagrus schlegeli). Gen Comp Endocrinol. 2008;159(1):38-45.
An KW, Lee J, Choi CY. Expression of three gonadotropin subunits and gonadotropin receptor mRNA during male-to-female sex change in the cinnamon clownfish, Amphiprion melanopus. Comp Biochem Physiol, Part A Mol Integr Physiol. 2010;156(4):407-15.

Avise JC. Hermaphroditism: A Primer on the Biology, Ecology, and Evolution of Dual Sexuality. New York: Columbia University Press; 2010.

Avise JC, Mank JE. Evolutionary perspectives on hermaphroditism in fishes. Sex Dev. 2009; 3(2-3):152-63.

Barata EN, Hubbard PC, Almeida OG, Miranda A, Canário AV. Male urine signals social rank in the Mozambique tilapia (Oreochromis mossambicus). BMC Biol. 2007;5:54.

Barata EN, Fine JM, Hubbard PC, Almeida OG, Frade P, Sorensen PW, et al. A sterol-like odorant in the urine of Mozambique tilapia males likely signals social dominance to females. J Chem Ecol. 2008;34(4):438-49.

Baron D, Cocquet J, Xia X, Fellous M, Guiguen Y, Veitia RA. An evolutionary and functional analysis of FoxL2 in rainbow trout gonad differentiation. J Mol Endocrinol. 2004;33(3): 705-15.

Best C, Ikert H, Kostyniuk DJ, Craig PM, Navarro-Martin L, Marandel L, et al. Epigenetics in teleost fish: From molecular mechanisms to physiological phenotypes. Comp Biochem Physiol B Biochem Mol Biol. 2018;224:21044.

Black MP, Reavis RH, Grober MS. Socially induced sex change regulates forebrain isotocin in Lythrypnus dalli. Neuroreport. 2004;15(1): 185-9.

Breton TS, Kenter LW, Greenlaw K, Montgomery J, Goetz GW, Berlinsky DL, et al. Initiation of sex change and gonadal gene expression in black sea bass (Centropristis striata) exposed to exemestane, an aromatase inhibitor. Comp Biochem Physiol A Mol Integrat Physiol. 2019;228:51-61.

Brown-Peterson NJ, Wyanski DM, Saborido-Rey F, Macewicz BJ, Lowerre-Barbieri SK. A standardized terminology for describing reproductive development in fishes. Mar Coast Fish. 2011;3(1):52-70.

Buston P. Social hierarchies: size and growth modification in clownfish. Nature. 2003; 424(6945):145-6.

Capel B. Vertebrate sex determination: evolutionary plasticity of a fundamental switch. Nat Rev Genet. 2017;18(11):675-89.

Casadevall M, Delgado E, Colleye O, Monserrat SB, Parmentier E. Histological study of the sex-change in the skunk clownfish Amphiprion akallopisos. TOFSJ. 2009;2(1):55-8

Casas L, Saborido-Rey F, Ryu T, Michell C, Ravasi T, Irigoien X. Sex change in clownfish: molecular insights from transcriptome analysis. Sci Rep. 2016;6:35461.

Castelli MA, Whiteley SL, Georges A, Holleley CE. Cellular calcium and redox regulation: the mediator of vertebrate environmental sex determination? Biol Rev Camb Philos Soc. 2020;95:680-95.

Chen CC, Fernald RD. Visual information alone changes behavior and physiology during social interactions in a cichlid fish (Astatotilapia burtoni). PLoS One. 2011;6(5):e20313.

Chen J, Xiao L, Peng C, Ye Z, Wang D, Yang Y, et al. Socially controlled male-to-female sex reversal in the protogynous orange-spotted grouper, Epinephelus coioides. J Fish Biol. 2019;94(3):414-21.

Chen J, Chen H, Peng C, Ye Z, Zhao M, Xiao L, et al. A highly efficient method of inducing sex change using social control in the protogynous orange-spotted grouper (Epinephelus coioides). Aquaculture. 2020a;517:734787. 
Chen J, Peng C, Yu Z, Xiao L, Yu Q, Li S, et al. The administration of cortisol induces female-tomale sex change in the protogynous orangespotted grouper, Epinephelus coioides. Front Endocrinol. 2020b;11:12.

Clayton RN, Popkin R, Fraser HM. Hypothalamic regulation of pituitary gonadotropin-releasing hormone receptors: effects of gonadotropin-releasing hormone immunoneutralization. Endocrinology. 1982;110:1116-23.

Clifton KE, Rogers L. Sex-specific mortality explains non-sex-change by large female Sparisoma radians. Anim Behav. 2008;75(2):e1e10.

Cole KS, Shapiro DY. Gonadal structure and population characteristics of the protogynous goby Coryphopterus glaucofraenum. Mar Biol. 1992;113(1):1-9.

Cole KS, Shapiro DY. Social faciliation and sensory mediation of adult sex change in a cryptic, benthic marine goby. J Experiment Mar Biol Ecol. 1995; 186(1):65-75.

Colleye O, Parmentier E. Overview on the diversity of sounds produced by clownfishes (Pomacentridae): Importance of acoustic signals in their peculiar way of life. PLoS One. 2012;7(11):e49179.

Colleye O, Frederich B, Vandewalle P, Casadevall M, Parmentier E. Agonistic sounds in the skunk clownfish Amphiprion akallopisos: size-related variation in acoustic features. Fish Biol. 2009;75:908-16.

Deangelis R, Gogola J, Dodd L, Rhodes JS. Opposite effects of nonapeptide antagonists on paternal behavior in the teleost fish Amphiprion ocellaris. Horm Behav. 2017;90:113-9.

DeAngelis R, Dodd L, Rhodes J. Nonapeptides mediate trade-offs in parental care strategy. Horm Behav. 2020;121:104717.

Devlin RH, Nagahama Y. Sex determination and sex differentiation in fish: An overview of genetic, physiological, and environmental influences. Aquaculture. 2002;208(3-4):191-364.

Dodd LD, Nowak E, Lange D, Parker CG, DeAngelis R, Gonzalez JA, et al. Active feminization of the preoptic area occurs independently of the gonads in Amphiprion ocellaris. Horm Behav. 2019;112:65-76.

Domingos JA, Budd AM, Banh QQ, Goldsbury JA, Zenger KR, Jerry DR. Sex-specific dmrt1 and cyp19al methylation and alternative splicing in gonads of the protandrous hermaphrodite barramundi. PLoS One. 2018; 13(9):e0204182.

Du JL, Lee YH, Yueh WS, Chang CF. Seasonal profiles of brain and pituitary gonadotropinreleasing hormone and plasma luteinizing hormone in relation to sex change of protandrous black porgy, Acanthopagrus schlegeli. Biol Reprod. 2005;72(4):922-31.

Erisman BE, Craig MT, Hastings PA. A Phylogenetic test of the size-advantage model: Evolutionary changes in mating behavior influence the loss of sex change in a fish lineage. Am Nat. 2009;174:E83-E99.
Erisman BE, Petersen CW, Hastings PA, Warner RR. Phylogenetic perspectives on the evolution of functional hermaphroditism in teleost fishes. Integr Comp Biol. 2013;53(4):736-54.

Escobar-Camacho D, Carleton KL. Sensory modalities in cichlid fish behavior. Curr Opin Behav Sci. 2015;6:115-24.

Ferreira IA, Poletto AB, Kocher TD, Mota-Velasco JC, Penman DJ, Martins C. Chromosome evolution in African cichlid fish: Contributions from the physical mapping of repeated DNAs. Cytogenet Genome Res. 2010;129(4): 314-22.

Forger NG. Epigenetic mechanisms in sexual differentiation of the brain and behaviour. Phi los Trans R Soc Lond B Biol Sci. 2016; 371(1688):20150114.

Frisch A. Sex-change and gonadal steroids in sequentially-hermaphroditic teleost fish. Rev Fish Biol Fisheries. 2004;14(4):481-99.

Frisch AJ, Walker SP, Mccormick MI, SolomonLane TK. Regulation of protogynous sex change by competition between corticosteroids and androgens: An experimental test using sandperch, Parapercis cylindrica. Horm Behav. 2007;52(4):540-5.

Gemmell NJ, Todd EV, Goikoetxea A, OrtegaRecalde O, Hore TA. Natural sex change in fish. Curr Top Dev Biol. 2019;134:71-117.

Georges A, L'Hôte D, Todeschini AL, Auguste A, Legois B, Zider A, et al. The transcription factor FOXL2 mobilizes estrogen signaling to maintain the identity of ovarian granulosa cells. Elife. 2014;3:1-19.

Ghiselin MT. The evolution of hermaphroditism among animals. Q Rev Biol. 1969;44(2):189_ 208.

Godwin J. Behavioural aspects of protandrous sex change in the anemonefish, Amphiprion melanopus, and endocrine correlates. Anim Behav. 1994;48(3):551-67.

Godwin J. Social determination of sex in reef fishes. Semin Cell Dev Biol. 2009;20(3):264-70.

Godwin J. Neuroendocrinology of sexual plasticity in teleost fishes. Front Neuroendocrinol. 2010;31(2):203-16.

Godwin JR, Thomas P. Sex change and steroid profiles in the protandrous anemonefish Amphiprion melanopus (Pomacentridae, Teleostei). Gen Comp Endocrinol. 1993;91(2): 144-57. 8405900

Godwin J, Thompson R. Nonapeptides and social behavior in fishes. Horm Behav. 2012;61(3): 230-8.

Godwin J, Crews D, Warner RR. Behavioural sex change in the absence of gonads in a coral reef fish. Proc Biol Sci. 1996;263(1377):1683-8.

Goikoetxea A, Todd EV, Gemmell NJ. Stress and sex: does cortisol mediate sex change in fish? Reproduction. 2017;154(6):R149-60.

Grosenick L, Clement TS, Fernald RD. Fish can infer social rank by observation alone. Nature. 2007;445(7126):429-32.
Guiguen Y, Fostier A, Piferrer F, Chang CF. Ovarian aromatase and estrogens: A pivotal role for gonadal sex differentiation and sex change in fish. Gen Comp Endocrinol. 2010;165(3): 352-66.

Han Y, Peng C, Wang L, Guo J, Lu M, Chen J, et al. Female-to-male sex reversal in orangespotted grouper (Epinephelus coioides) caused by overexpressing of Amh in vivo. Biol Reprod. 2018;99:1205-15.

Hattori RS, Fernandino JI, Kishii A, Kimura H, Kinno T, Oura M, et al. Cortisol-induced masculinization: Does thermal stress affect gonadal fate in pejerrey, a teleost fish with temperature-dependent sex determination? PLoS One. 2009;4(8):e6548.

Hayashi Y, Kobira H, Yamaguchi T, Shiraishi E, Yazawa T, Hirai T, et al. High temperature causes masculinization of genetically female medaka by elevation of cortisol. Mol Reprod Dev. 2010;77(8):679-86.

He CL, Du JL, Wu GC, Lee YH, Sun LT, Chang CF. Differential Dmrt1 transcripts in gonads of the protandrous black porgy, Acanthopagrus schlegeli. Cytogenet Genome Res. 2003;101(3-4):309-13.

Herpin A, Schartl M. Dmrt1 genes at the crossroads: a widespread and central class of sexual development factors in fish. FEBS J. 2011; 278(7):1010-9.

Hodge JR, Santini F, Wainwright PC. Correlated evolution of sex allocation and mating system in wrasses and parrotfishes. Am Nat. 2020; 196(1):57-73.

Horiguchi R, Nozu R, Hirai T, Kobayashi Y, Nakamura M. Expression patterns of sex differentiation-related genes during gonadal sex change in the protogynous wrasse, Halichoeres trimaculatus. Gen Comp Endocrinol. 2018;257:67-73.

Huang X, Guo Y, Shui Y, Gao S, Yu H, Cheng H, et al. Multiple alternative splicing and differential expression of dmrtl during gonad transformation of the rice field eel. Biol Reprod. 2005;73(5):1017-24

Iwata E, Nagai Y, Sasaki H. Social rank modulates brain arginine vasotocin immunoreactivity in false clown anemonefish (Amphiprion ocellaris). Fish Physiol Biochem. 2010;36(3):33745.

Iwata E, Suzuki N. Steroidal regulation of the aromatase gene and dominant behavior in the false clown anemonefish Amphiprion ocellaris. Fish Sci. 2020;86(3):457-63.

Kamiya T, Kai W, Tasumi S, Oka A, Matsunaga T, Mizuno N, et al. A Trans-species missense SNP in Amhr2 is associated with sex determination in the tiger pufferfish, Takifugu rubripes (Fugu). PLoS Genet. 2012;8(7): e1002798.

Kasumyan AO. Tactile reception and behavior of fish. J Ichthyol. 2011;51(11):1035-103.

Kazancioĝlu E, Alonzo SH. A comparative analysis of sex change in labridae supports the size advantage hypothesis. Evolution. 2010;64: 2254-64. 
Kobayashi Y, Sunobe T, Kobayashi T, Nagahama Y, Nakamura M. Gonadal structure of the serial-sex changing gobiid fish Trimma okinawae. Dev Growth Differ. 2005;47(1):7-13.

Kobayashi Y, Nakamura M, Sunobe T, Usami T, Kobayashi T, Manabe H, et al. Sex change in the gobiid fish is mediated through rapid switching of gonadotropin receptors from ovarian to testicular portion or vice versa. Endocrinology. 2009;150(3):1503-11.

Kobayashi Y, Alam MA, Horiguchi R, Shimizu A, Nakamura M. Sexually dimorphic expression of gonadotropin subunits in the pituitary of protogynous honeycomb grouper (Epinephelus merra): Evidence that follicle-stimulating hormone (FSH) induces gonadal sex change. Biol Reprod. 2010;82:1030-6.

Kobayashi Y, Nagahama Y, Nakamura M. Diversity and plasticity of sex determination and differentiation in fishes. Sex Dev. 2013;7(1-3): $115-25$.

Kojima Y, Bhandari RK, Kobayashi Y, Nakamura M. Sex change of adult initial-phase male wrasse, Halichoeres trimaculatus, by estradiol-17 beta treatment. Gen Comp Endocrinol. 2008;156(3):628-32.

Kroon FJ, Munday PL, Pankhurst NW. Steroid hormone levels and bi-directional sex change in Gobiodon histrio. J Fish Biol. 2003;62(1): 153-67.

Kroon FJ, Munday PL, Westcott DA, Hobbs JP, Liley NR. Aromatase pathway mediates sex change in each direction. Proc Biol Sci. 2005; 272(1570):1399-405.

Kuwamura T, Nakashima Y. New aspects of sex change among reef fishes: Recent studies in Japan. Environ Biol Fishes. 1998;52:125-35.

Kuwamura T, Sunobe T, Sakai Y, Kadota T, Sawada K. Hermaphroditism in fishes: an annotated list of species, phylogeny, and mating system. Ichthyol Res. 2020;67(3):341-60.

Lamm MS, Liu H, Gemmell NJ, Godwin JR. The need for speed: Neuroendocrine regulation of socially-controlled sex change. Integr Comp Biol. 2015;55(2):307-22.

Larson ET. Neuroendocrine regulation in sexchanging fishes. In: Norris D, Lopez K(eds). Hormones and Reproduction of Vertebrates. Amsterdam: Elsevier; 2011. p. 149-68.

Lee YH, Du JL, Yueh WS, Lin BY, Huang JD, Lee $\mathrm{CY}$, et al. Sex change in the protandrous black porgy, Acanthopagrus schlegeli: a review in gonadal development, estradiol, estrogen receptor, aromatase activity and gonadotropin. J Exp Zool. 2001;290(7):715-26.

Lee YH, Yueh WS, Du JL, Sun LT, Chang CF. Aromatase inhibitors block natural sex change and induce male function in the protandrous black porgy, Acanthopagrus schlegeli Bleeker: Possible mechanism of natural sex change. Biol Reprod. 2002;66:174954.

Lenkov K, Lee MH, Lenkov OD, Swafford A, Fernald RD. Epigenetic DNA methylation linked to social dominance. PLoS One. 2015;10(12): e0144750.
Li MH, Yang HH, Li MR, Sun YL, Jiang XL, Xie $\mathrm{QP}$, et al. Antagonistic roles of Dmrtl and Foxl2 in sex differentiation via estrogen production in tilapia as demonstrated by TALENs. Endocrinology. 2013; 154(12): 4814-25.

Lin Q, Mei J, Li Z, Zhang X, Zhou L, Gui JF. Distinct and cooperative roles of amh and dmrt1 in self-renewal and differentiation of male germ cells in zebrafish. Genetics. 2017;207(3): 1007-22.

Liu H, Lamm MS, Rutherford K, Black MA, Godwin JR, Gemmell NJ. Large-scale transcriptome sequencing reveals novel expression patterns for key sex-related genes in a sexchanging fish. Biol Sex Differ. 2015;6:26.

Liu H, Todd EV, Lokman PM, Lamm MS, Godwin JR, Gemmell NJ. Sexual plasticity: A fishy tale. Mol Reprod Dev. 2017;84(2):171-94.

Lorenzi V, Earley RL, Grober MS. Preventing behavioural interactions with a male facilitates sex change in female bluebanded gobies, Lythrypnus dalli. Behav Ecol Sociobiol. 2006; 59(6):715-22.

Lorenzi V, Earley RL, Grober MS. Differential responses of brain, gonad and muscle steroid levels to changes in social status and sex in a sequential and bidirectional hermaphroditic fish. PLoS One. 2012;7(12):e51158.

Lutnesky MMF. Density-dependent protogynous sex change in territorial-haremic fishes: models and evidence. Behavioral Ecology. 1994; 5(4):375-83.

Manousaki T, Tsakogiannis A, Lagnel J, Sarropoulou E, Xiang JZ, Papandroulakis N, et al. The sex-specific transcriptome of the hermaphrodite sparid sharpsnout seabream (Diplodus puntazzo). BMC Genomics. 2014;15: 655.

Maruska KP, Fernald RD. Steroid receptor expression in the fish inner ear varies with sex, social status, and reproductive state. BMC Neurosci. 2010;11:58.

Maruska KP, Fernald RD. Contextual chemosensory urine signaling in an African cichlid fish. J Exp Biol. 2012;215(Pt 1):68-74.

Maruska KP, Ung US, Fernald RD. The African cichlid fish Astatotilapia burtoni uses acoustic communication for reproduction: Sound production, hearing, and behavioral significance. PLoS One. 2012;7(5):e37612.

Maruska K, Soares MC, Lima-Maximino M, Henrique de Siqueira-Silva D, Maximino C. Social plasticity in the fish brain: Neuroscientific and ethological aspects. Brain Res. 2019;1711: $156-72$.

Masuyama H, Yamada M, Kamei Y, FujiwaraIshikawa $\mathrm{T}$, Todo $\mathrm{T}$, Nagahama $\mathrm{Y}$, et al. Dmrtl mutation causes a male-to-female sex reversal after the sex determination by Dmy in the medaka. Chromosome Res. 2012;20(1): 163-76.

Matson CK, Zarkower D. Sex and the singular DM domain: insights into sexual regulation, evolution and plasticity. Nat Rev Genet. 2012; 13(3):163-74
Matson CK, Murphy MW, Sarver AL, Griswold MD, Bardwell VJ, Zarkower D. DMRT1 prevents female reprogramming in the postnatal mammalian testis. Nature. 2011;476(7358): 101-4.

Miyake Y, Fukui Y, Kuniyoshi H, Sakai Y, Hashimoto $\mathrm{H}$. Examination of the ability of gonadal sex change in primary males of the diandric wrasses Halichoeres poecilopterus and Halichoeres tenuispinis: Estrogen implantation experiments. Zool Sci. 2008;25(2):220-4.

Miyaki Y, Sakai Y, Kuniyoshi H. Molecular cloning and expression profile of sex-specific genes, figla and dmrt1, in the protogynous hermaphroditic fish, Halichoeres poecilopterus. Zool Sci. 2012;29:690-710.

Molloy PP, Goodwin NB, Côté IM, Reynolds JD, Gage MJ. Sperm competition and sex change: A comparative analysis across fishes. Evolution. 2007;61(3):640-52.

Morinaga C, Saito D, Nakamura S, Sasaki T, Asakawa S, Shimizu N, et al. The hotei mutation of medaka in the anti-Mullerian hormone receptor causes the dysregulation of germ cell and sexual development. Proc Natl Acad Sci USA. 2007;104(23):9691-6.

Muncaster S, Norberg B, Andersson E. Natural sex change in the temperate protogynous Ballan wrasse Labrus bergylta. J Fish Biol. 2013; 82(6): 1858-70.

Munday PL, Buston PM, Warner RR. Diversity and flexibility of sex-change strategies in animals. Trends Ecol Evol. 2006;21(2):89-95.

Munday PL, Kuwamura T, Kroon FJ. Bi-directional sex change in marine fishes. In: Cole KS, editor. Reproduction and Sexuality in Marine Fishes: Patterns and Processes. Berkley: University of California Press; 2010. p. 241-71.

Muñoz RC. Testing a new version of the size-advantage hypothesis for sex change: sperm competition and size-skew effects in the bucktooth parrotfish, Sparisoma radians. Behavioral Ecology. 2004;15(1):129-36.

Muñoz RC, Warner RR. A new version of the sizeadvantage hypothesis for sex change: incorporating sperm competition and size-fecundity skew. Am Nat. 2003;161:749-61.

Nakamoto M, Matsuda M, Wang DS, Nagahama Y, Shibata N. Molecular cloning and analysis of gonadal expression of Foxl2 in the medaka, Oryzias latipes. Biochem Biophys Res Commun. 2006;344(1):353-61.

Nakamura S, Watakabe I, Nishimura T, Picard JY, Toyoda A, Taniguchi Y, et al. Hyperproliferation of mitotically active germ cells due to defective anti-Müllerian hormone signaling mediates sex reversal in medaka. Development. 2012;139(13):2283-7.

Nelson JS, Grande TC, Wilsons MVH. Fishes of the World, ed 5. Hoboken: Wiley; 2016.

Nikonov AA, Maruska KP. Male dominance status regulates odor-evoked processing in the forebrain of a cichlid fish. Sci Rep. 2019;9(1): 5083. 
Nozu R, Nakamura M. Cortisol administration induces sex change from ovary to testis in the protogynous wrasse, Halichoeres trimaculatus. Sex Dev. 2015;9(2):118-24.

Ohta K, Hirano M, Mine T, Mizutani H, Yamaguchi A, Matsuyama M. Body color change and serum steroid hormone levels throughout the process of sex change in the adult wrasse, Pseudolabrus sieboldi. Mar Biol. 2008;153(5):843-52.

Ortega-Recalde O, Goikoetxea A, Hore TA, Todd EV, Gemmell NJ. The genetics and epigenetics of sex change in fish. Annu Rev Anim Biosci. 2020;8:47-69.

Pandian TJ. Sexuality in Fishes. Boca Raton, FL: CRC Press; 2010.

Parmentier E, Colleye O, Fine ML, Frédérich B, Vandewalle P, Herrel A. Sound production in the clownfish Amphiprion clarkii. Science. 2007;316(5827): 1006 .

Peng C, Wang Q, Shi H, Chen J, Li S, Zhao H, et al. Natural sex change in mature protogynous orange-spotted grouper (Ephinephelus coloides): gonadal restructuring, sex hormone shifts and gene profiles. J Fish Biol. 2020;97: 785-93.

Pfennig F, Standke A, Gutzeit HO. The role of Amh signaling in teleost fish--Multiple functions not restricted to the gonads. Gen Comp Endocrinol. 2015;223:87-107.

Pla S, Benvenuto C, Capellini I, Piferrer F. A phylogenetic comparative analysis on the evolution of sequential hermaphroditism in seabreams (Teleostei: Sparidae). Sci Rep. 2020;10(1):1-12.

Rajakumar A, Senthilkumaran B. Steroidogenesis and its regulation in teleost - a review. Fish Physiol Biochem. 2020;46(3):803-18.

Ratnu VS, Emami MR, Bredy TW. Genetic and epigenetic factors underlying sex differences in the regulation of gene expression in the brain. J Neurosci Res. 2017;95(1-2):301-10.

Ravi P, Jiang J, Liew WC, Orbán L. Small-scale transcriptomics reveals differences among gonadal stages in Asian seabass (Lates calcarifer). Reprod Biol Endocrinol. 2014;12:5.

Ross RM. The evolution of sex-change mechanisms in fishes. Environ Biol Fish. 1990;29(2): $81-93$.

Sadovy Y, Shapiro DY. Criteria for the diagnosis of hermaphroditism in fishes. Copeia. 1987; 1987(1):136-56.

Sadovy De Mitcheson Y, Liu M. Functional hermaphroditism in teleosts. Fish Fish. 2008;9: $1-43$.

Sato T, Kobayashi M, Takebe T, Hirai N, Okuzawa K, Sawaguchi S, et al. Induction of femaleto-male sex change in a large protogynous fish, Choerodon schoenleinii. Mar Ecol. 2018; 39(1):e12484

Semsar K, Godwin J. Social influences on the arginine vasotocin system are independent of gonads in a sex-changing fish. J Neurosci. 2003;23(10):4386-93.
Shapiro DY. Sex change as an alternative life-history style. In: Bruton MN (ed). Alternative Life-History Styles of Animals. Dordrecht: Springer Netherlands; 1989. p. 177-95.

Shi Y, Zhang Y, Li S, Liu Q, Lu D, Liu M, et al. Molecular identification of the Kiss2/Kiss1ra system and its potential function during $17 \mathrm{al}-$ pha-methyltestosterone-induced sex reversal in the orange-spotted grouper, Epinephelus coioides. Biol Reprod. 2010;83(1):63-74.

Shiraishi E, Yoshinaga N, Miura T, Yokoi H, Wakamatsu Y, Abe S-I, et al. Müllerian inhibiting substance is required for germ cell proliferation during early gonadal differentiation in medaka (Oryzias latipes). Endocrinology. 2008; 149:1813-9.

Siegfried KR. In search of determinants: gene expression during gonadal sex differentiation. J Fish Biol. 2010;76(8):1879-902.

Simões JM, Barata EN, Harris RM, O'Connell LA, Hofmann HA, Oliveira RF. Social odors conveying dominance and reproductive information induce rapid physiological and neuromolecular changes in a cichlid fish. BMC Genomics. 2015;16:114.

Skaar KS, Nóbrega RH, Magaraki A, Olsen LC, Schulz RW, Male R. Proteolytically activated, recombinant anti-Mullerian hormone inhibits androgen secretion, proliferation, and differentiation of spermatogonia in adult zebrafish testis organ cultures. Endocrinology. 2011;152(9):3527-40.

Solomon-Lane TK, Crespi EJ, Grober MS. Stress and serial adult metamorphosis: Multiple roles for the stress axis in socially regulated sex change. Front Neurosci. 2013;7:210-2.

Taborsky B, Tschirren L, Meunier C, AubinHorth N. Stable reprogramming of brain transcription profiles by the early social environment in a cooperatively breeding fish. Proc Biol Sci. 2013;280(1753):20122605

Taylor BM. Drivers of protogynous sex change differ across spatial scales. Proc Biol Sci. 2014; 281(1775):20132423.

Taylor RG, Whittington JA, Grier HJ, Crabtree RE. Age, growth, maturation, and protandric sex reversal in common snook, Centropomus undecimalis, from the east and west coasts of South Florida. Fish Bull. 2000;98:612-24.

Thomas JT, Liu H, Todd EV, Gemmell NJ. Sex change in fish. In: Skinner M, editor. Encyclopedia of Reproduction, ed 2. Amsterdam: Elsevier; 2018. p. 192-7.

Thomas JT, Todd EV, Muncaster S, Lokman PM, Damsteegt EL, Liu H, et al. Conservation and diversity in expression of candidate genes regulating socially-induced female-male sex change in wrasses. PeerJ. 2019;7:e7032.

Todd EV, Liu H, Muncaster S, Gemmell NJ. Bending genders: The biology of natural sex change in fish. Sex Dev. 2016;10(5-6):22341.

Todd EV, Ortega-Recalde O, Liu H, Lamm MS, Rutherford KM, Cross H, et al. Stress, novel sex genes, and epigenetic reprogramming orchestrate socially controlled sex change. Sci Adv. 2019;5:1-14.
Tsakogiannis A, Manousaki T, Lagnel J, Sterioti A, Pavlidis M, Papandroulakis N, et al. The transcriptomic signature of different sexes in two protogynous hermaphrodites: Insights into the molecular network underlying sex phenotype in fish. Sci Rep. 2018;8:3564.

Tsakogiannis A, Manousaki T, Lagnel J, Papanikolaou N, Papandroulakis N, Mylonas CC, et al. The gene toolkit implicated in functional sex in sparidae hermaphrodites: Inferences from comparative transcriptomics. Front Genet. 2018;9:749.

Ungewitter EK, Yao HH. How to make a gonad: Cellular mechanisms governing formation of the testes and ovaries. Sex Dev. 2013;7(1-3): $7-20$.

Villegas-Ríos D, Alonso-Fernández A, Domínguez-Petit R, Saborido-Rey F. Intraspecific variability in reproductive patterns in the temperate hermaphrodite fish, Labrus bergylta. Mar Freshwater Res. 2013;64(12):1156.

Wang DS, Kobayashi T, Zhou LY, Paul-Prasanth B, Ijiri S, Sakai F, et al. Foxl2 up-regulates aromatase gene transcription in a female-specific manner by binding to the promoter as well as interacting with Ad4 binding protein/steroidogenic factor 1. Mol Endocrinol. 2007; 21(3):712-25.

Warner RR. The adaptive significance of sequential hermaphroditism in animals. Am Nat. 1975;109(965):61-82.

Warner RR. Mating Behavior and Hermaphroditism in Coral Reef Fishes: The diverse forms of sexuality found among tropical marine fishes can be viewed as adaptations to their equally diverse mating systems. Am Sci. 1984;72:128-36.

Warner RR. Sex change in fishes: hypotheses, evidence, and objections. Environ Biol Fish. 1988a;22(2):81-90.

Warner RR: Sex change and the size-advantage model. Trends Ecol Evol. 1988b;3(6):133-6.

Warner RR, Swearer SE. Social control of sex change in the bluehead wrasse, Thalassoma bifasciatum (Pisces: Labridae). Biol Bull. 1991;181(2): 199-204.

Webster KA, Schach U, Ordaz A, Steinfeld JS, Draper BW, Siegfried KR. Dmrt1 is necessary for male sexual development in zebrafish. Dev Biol. 2017;422(1):33-46.

Weltzien F-A, Andersson E, Andersen Ø, Shalchian-Tabrizi K, Norberg B. The brain-pituitary-gonad axis in male teleosts, with special emphasis on flatfish (Pleuronectiformes). Comp Biochem Physiol Part A Mol Integr Physiol. 2004;137:447-77.

Wong T-T, Ijiri S, Zohar Y. Molecular biology of ovarian aromatase in sex reversal: Complementary DNA and $5^{\prime}$-flanking region isolation and differential expression of ovarian aromatase in the gilthead seabream (Sparus aurata). Biol Reprod. 2006;74:857-64.

Wu GC, Chiu PC, Lyu YS, Chang CF. The Expression of amh and amhr2 is associated with the development of gonadal tissue and sex change in the protandrous black porgy, Acanthopagrus schlegeli. Biol Reprod. 2010a; 83(3):443-53. 
Wu GC, Tomy S, Lee MF, Lee YH, Yueh WS, Lin $\mathrm{CJ}$, et al. Sex differentiation and sex change in the protandrous black porgy, Acanthopagrus schlegeli. Gen Comp Endocrinol. 2010b; 167(3):417-21.

Wu GC, Li HW, Luo JW, Chen C, Chang CF. The potential role of Amh to prevent ectopic female development in testicular tissue of the protandrous black porgy, Acanthopagrus schlegelii. Biol Reprod. 2015;92(6):158.

Wu GC, Li HW, Huang CH, Lin HJ, Lin CJ, Chang CF. The testis is a primary factor that contributes to epigenetic modifications in the ovaries of the protandrous black porgy, Acanthopagrus schlegelii. Biol Reprod. 2016;94(6): 132.
Wu GC, Li HW, Tey WG, Lin CJ, Chang CF. Expression profile of amh/Amh during bi-directional sex change in the protogynous orangespotted grouper Epinephelus coioides. PLoS One. 2017;12(10):e0185864.

Xia W, Zhou L, Yao B, Li CJ, Gui JF. Differential and spermatogenic cell-specific expression of DMRT1 during sex reversal in protogynous hermaphroditic groupers. Mol Cell Endocrinol. 2007;263(1-2):156-72.

Yamaguchi T, Yamaguchi S, Hirai T, Kitano T. Follicle-stimulating hormone signaling and Foxl2 are involved in transcriptional regulation of aromatase gene during gonadal sex differentiation in Japanese flounder, Paralichthys olivaceus. Biochem Biophys Res Commun. 2007;359(4):935-40.
Yamaguchi T, Yoshinaga N, Yazawa T, Gen K, Kitano T. Cortisol is involved in temperature-dependent sex determination in the Japanese flounder. Endocrinology. 2010;151(8):3900-8.

Zhang Y, Zhang S, Liu Z, Zhang L, Zhang W. Epigenetic modifications during sex change repress gonadotropin stimulation of Cyp19ala in a teleost ricefield eel (Monopterus albus). Endocrinology. 2013;154(8):2881-90.

Zhang K, Xu J, Zhang Z, Huang Y, Ruan Z, Chen $S$, et al. A comparative transcriptomic study on developmental gonads provides novel insights into sex change in the protandrous black porgy (Acanthopagrus schlegelii). Genomics. 2019;111(3):277-83. 